\title{
Article
}

\section{Seeing Double? A Practice-Based Investigation into Twins experiences of Sporting Talent Development}

Taylor, Robin David, Carson, Howie J and Collins, Dave Available at http://clok.uclan.ac.uk/32851/

Taylor, Robin David ORCID: 0000-0001-9530-8355, Carson, Howie J and Collins, Dave (2020) Seeing Double? A Practice-Based Investigation into Twins experiences of Sporting Talent Development. International Sport Coaching Journal . ISSN 2328-918X

It is advisable to refer to the publisher's version if you intend to cite from the work. http://dx.doi.org/10.1123/iscj.2019-0066

For more information about UCLan's research in this area go to http://www.uclan.ac.uk/researchgroups/ and search for <name of research Group>.

For information about Research generally at UCLan please go to http://www.uclan.ac.uk/research/

All outputs in CLoK are protected by Intellectual Property Rights law, including Copyright law. Copyright, IPR and Moral Rights for the works on this site are retained by the individual authors and/or other copyright owners. Terms and conditions for use of this material are defined in the policies page.

\section{CLoK}

Central Lancashire online Knowledge www.clok.uclan.ac.uk

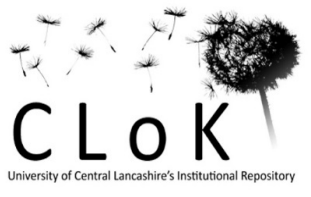


Running Head: TWINS AND TALENT DEVELOPMENT

Seeing Double? A Practice-Based Investigation into Twins experiences of Sporting Talent Development

\author{
Robin D. Taylor ${ }^{* 1}$, Howie J. Carson ${ }^{2}$ \& Dave Collins ${ }^{2,3}$ \\ ${ }^{1}$ Institute for Coaching and Performance, University of Central Lancashire \\ ${ }^{2}$ Moray House School of Education and Sport, The University of Edinburgh \\ ${ }^{3}$ Grey Matters Performance Ltd.
}

*Correspondence concerning this paper should be addressed to Robin Taylor, 006 Greenbank Building, University of Central Lancashire, Preston, PR1 2HE, United Kingdom. Email: RDTaylor2@uclan.ac.uk 


\section{Abstract}

While there is an established body of research on twins within the wider social science domain, scarce attention has been applied to this relationship within sport coaching practice. Specifically, this is apparent during talent development, despite a growing empirical interest toward the developmental impact of age-gapped siblings on sporting success. Accordingly, this study explored potential mechanisms through which the twin relationship may impact on talent development. Longitudinal observation of two twin sets (one monozygotic and one dizygotic) took place within a UK regional hockey performance centre training environment. Observations were used to inform semi-structured interviews with twins and their parents, which facilitated the interpretation of observations and exploration of the relationship, before a codebook thematic analysis was conducted. Findings revealed several themes (regularity of interaction, emotional interpersonal skills, rivalry, skill development, communication, and type of separation) consistent with previous studies, alongside two new themes; namely, conflict and identity. The study highlights the complex and individualized nature of the sibling subsystem, illuminating the possible impact of twin type on several themes, and highlights the potential for observations as a practice-based tool for coaches to consider when individualizing the talent development process.

Key words: coaching, family systems theory, pragmatism, siblings, self-regulation 
1 Seeing double? A practice-based investigation into twin's experiences of sporting talent development

Twin studies have long been recognized as valuable in examining the coactive influences of genes and the environment on specific characteristics (Galton, 1875). Most common within study designs is the recording of differences between monozygotic (MZ) and dizygotic (DZ) twin sets (e.g., Huguet et al., 2017). Indeed, these differences are perhaps of most significant interest to social scientists during or following important developmental processes or events. Certainly, within the psychology domain, twin research is a well utilized paradigm for this purpose (e.g., Haworth et al., 2013). However, there is a dearth of twin research within sport coaching and talent development (TD; Baker \& Horton, 2004), despite recognition and increasing interest towards sibling influences within these challenging and transitory environments (e.g., Blazo et al., 2014; Taylor et al., 2017). As such, this paper focusses on the specific twin relationship during the TD coaching process.

\section{Family Systems Theory: Its Application to Sport Coaching}

Recent identification of family systems theory (FST; Bowen, 1978) as a lens to further understand TD in sport (cf. Taylor \& Collins, 2015) has promoted theory-driven enquiry into the role of siblings (Blazo \& Smith, 2018). FST views family members as part of an inherently and emotionally connected unit, whose relationship strength are characterized by dynamic boundaries, existing along a continuum ranging from enmeshed (i.e., low influence from outside the relationship) to permeable (i.e., high influence from outside the relationship). FST suggests an interactive relationship between individuals' thoughts, feelings, and actions across any given time course of events. Accordingly, for coaches, understanding an individual, what they bring to the TD pathway, and how they develop within it, should also consider the dynamic of their closest social group, the family. From a TD perspective, providing individualized support is well accepted as the most optimal 
coaching approach to achieving success along a pathway (Phillips et al., 2010). However, in acknowledging the propositions of FST, developments within the formal Talent Development Environment (TDE) should ideally be considered by coaches alongside other informal/supplementary TDEs (e.g., the home). With this in mind, understanding if and how progress along the TD pathway can be positively - and perhaps uniquely in contrast to the input of coaches - impacted on when not "seen" to be training, offers a different but potentially useful resource for future developments in this area. In short, should the coach make best use of interactions (cf. Bailey et al., 2010) through the emotionally-bound relations present within the family?

\section{Siblings in Sport}

In light of retrospective research, siblings have been found to be important for achieving elite success (cf. Collins et al., 2016). For example, Nelson and Strachan (2017) explored how siblings influence elite youth sport participation. Athletes participating in the same sport as their sibling(s) developed a much deeper understanding of each other and experiences endured which were both positive (e.g., relationship growth and understanding) and negative (e.g., sibling competition and emotional response). Furthermore, siblings offered emotional support, guidance, and, in relation to the older sibling, a role model for participation and development. Moreover, Davis and Meyer (2008) explored the psychological impact of elite, on-field, and same-sex sibling competition. Their findings also presented concurrent positive (i.e., closeness and positive regard) and negative (i.e., dropout due to rivalry and disregard) characteristics within the relationship. Finally, Taylor et al.'s (2018) longitudinal study of four sibling dyads where both were in a TDE, revealed the interactional context (e.g., training and play), emotional interpersonal skills (e.g., closeness and support), skill development (e.g., mentoring and co-operation), communication (e.g., instruction and discussion), rivalry (e.g., competition and performance), and resilience (e.g., 
51 development and test) to be perceived as positive processes to TD. In support of the need for

52 individual consideration, the longitudinal nature exposed variations in frequency and importance of characteristics within and across the sibling relationships during TD. In summary, siblings seem to offer a much more diverse influence on TD, certainly when compared to the heavily considered role of parents (cf. Knight, 2017) and, therefore, should be considered by coaches, alongside parental involvement. However, the emergent and exploratory state of evidence in this area still leaves important questions unanswered and factors needing to be accounted for, such as sibling type (e.g., twins).

\section{Why Twins? An Overview of Research}

Contemporary accounts consider the active role of twins in shaping their social environments and how they negotiate the process of being a twin through interactions with each other (Bacon, 2010). Interestingly, study has revealed differential impacts of twin type, with $\mathrm{MZ}$ more likely to be content with their similar identity views (not only physiological) than DZ twins, who seek to differentiate themselves both through behavior and personality (Felson, 2014). Furthermore, Fortuna et al. (2010) suggest that variables other than genetic similarity may play a role in differentiating twins from age-gapped siblings, emphasizing the unique twin bond. For example, twins are required to interact with a sibling who has similar developmental markers; increasing the likelihood of common interests at each development stage, leading to a more intimate bond, and/or heightening competition between twins in comparison to age-gapped siblings. Notably, in either case, there is greater opportunity for a more meaningful relationship, be it positive or negative (Lytton, 1980). As such, this suggests that twin relationships can serve a nurturing function uncommon among non-twins (Ainslie, 1997; Tancredy \& Fraley, 2006), which suggests the need to consider this specific sibling type alongside age-gapped siblings within coaching practice. 
Occurring approximately once in every 65 births (ONS, 2016), twins are often assumed to have a relationship which is generally close, co-operative, and harmonious (Segal, 2000). Indeed, Noble et al. (2017, p. 345) suggested that being a twin is "one of the most unique and transformative developmental sibling relationships an individual can experience". These points suggest that twin relationships during TD might offer a subtle, but meaningful, difference to previous research with age-gapped siblings which serves to increase the complexity within TD. However, as yet, there is little twin research related to "excellence" in achievement and none within the context of sporting TD (Baker \& Horton, 2004). Considering the impact of the twin relationship on potential mechanisms for TD and exploring how such a relationship impacts on its permeability, would, therefore, contribute to the emergent coaching literature. Therefore, exploring this relationship within, and away from, the formal TDE was seen as a beneficial next step to informing effective coach decision making when applicable.

\section{Coach Decision Making to Support Optimal Talent Development}

So far, we have introduced the notion of family and, more specifically, siblings as being important agents within TD. Explicitly, we have identified these relationships as being complex and individualized in nature. Considering our aim of informing coaches' knowledge on TD, it is, therefore, also important to recognize the holistic and individualized needs of athletes in general within TD. Indeed, understanding how literature on the sibling relationship can be contextualized within TD more broadly, can better support coaches when planning for and/or evaluating the use of training and resources on a sport-by-sport and athlete-by-athlete basis (cf. Ackerman, 2014).

While a rare minority of athletes might have a seamless journey to the top of their sport, research has revealed that for the majority, the journey along a TD pathway is characteristically nonlinear, often unpredictable, and notably challenging (Abbott et al., 2005; 
Davids \& Baker, 2007). Furthermore, some TD researchers have explained such naturally occurring or designed challenges as necessary means (at an age and stage appropriate level) to demonstrate and learn a range of characteristics that are useful to future inevitable setbacks (of varying degrees; cf. Collins \& MacNamara, 2012). A phrase commonly used to describe this type of TD pathway is a "rocky road", which reflects inevitable changes in the rate of progress at times, transitory periods, and the need to be equipped with and know how to demonstrate different physical, psychological, and social skills to navigate the many barriers ahead (Bailey et al., 2010). Not only do challenges present across these domains, they are more accurately presented as interactive factors, which has led Bailey et al. to characterize TD by complex bio(physical)-psycho-social interactions. Consequently, expert coaching practice is now more commonly understood as being largely underpinned by a nuanced, epistemologically sophisticated, and contextually-derived decision making process as opposed to the application of a "one-size fits all” approach (Cruickshank \& Collins, 2016). Therefore, to make best use of any findings emanating from twin, as opposed to agegapped sibling, research, it is necessary to equip coaches with an approach or perspective that is coherent with the appreciation and understanding of complex interactions. One approach is the Professional judgement and decision making (PJDM) approach which emphasizes, above everything else, the importance of coaches considering why they are taking actions at that time, and any alternatives they might consider (cf. Collins \& Collins, 2015). Therefore, this approach caters for the inevitable nonlinearity of TD. An example of this can be seen in growth spurts in young athletes. Consider that growth spurt timing can be different across athletes, which can impact psychologically (e.g., self-efficacy), and also socially (e.g., team position or perceived status). Within the context of the sibling relationship, such an event might change the interaction through formal (e.g., training) and informal (e.g., in the garden) settings, which constitutes a large proportion of time during TD. If growth spurts occurred 
simultaneously, the relationship may become more enmeshed by the siblings assisting and supporting each other through the transition. If not, however, this could foster a more permeable and unhealthily competitive relationship. Therefore, such consideration is not simplistic and requires coaches to have an understanding of the complex nature of TD and the individual sibling relationships under consideration, over and above the other essentials of pedagogy and the sport itself (Abraham et al., 2006). In short, an underpinning knowledge of the individual, sport, and situational demands enables the coach to better anticipate, plan for, deliver, and revise practice as a hallmark of expert coaching.

\section{Methodological Considerations}

The need to examine cases intra-individually is not novel within sport (Kinugasa, 2013), but does challenge the notion of generalization and, therefore, the robustness of impact on TD. However, such design is consistent with the nonlinear and individualized nature of TD, where variability between individuals can reveal important complexities needing careful consideration by coaches within the applied context (Collins et al., 2015). Furthermore, within the social sciences, it is argued that more discoveries have arisen from intense observation than from statistics applied to large groups (Normand, 2016). Therefore, with the aim to bridge the gap between formal and informal TDEs, we drew upon research by Winter and Collins (2015) who highlighted that practice-derived knowledge can support and direct coaches in a contextually fitting manner. So far, studies of siblings and TD have yet to incorporate such an approach; instead solely focusing on interviews for data collection. Therefore, the purpose of this paper was to compare findings from the TD sibling literature with those of twins within the same TDE by employing practice-based inquiry as a novel approach to how coaches can explore the potential role of siblings in TD.

\section{Method}


Reflecting the aims outlined above, the present study employed a pragmatic approach.

Unlike other philosophical research approaches, pragmatism does not prioritize ontological or epistemological issues (Bryant, 2009). Instead, focusing on the extent to which shared knowledge can be generated in order to produce useful applied implications that can make a meaningful difference to practice (Bryant, 2009; Morgan, 2007). As such, pragmatism shapes all aspects of the research process, with a key focus on uncovering practical solutions and using theory to support applied discoveries (Giacobbi et al., 2005). Here, the role of the corresponding author was to become a co-constructor of knowledge with the participant(s) (Giacobbi et al., 2005); a process facilitated by being a head coach within the TDE examined in this study. This was beneficial to the quality of findings, since it is important that the researcher has credibility within, and understands, the environment (May, 2011). Without such insight there is the potential for weakened theoretical sensitivity and reduced quality of findings (May, 2011). Again, reflecting a pragmatic approach to this investigation, a mixedmethods procedure was adopted considering the scarce evidence on twins in TDEs. Accordingly, examinations of twin sets took place through an in-depth case-study approach using both observations and interviews, to afford a nuanced view of reality (Flyvbjerg, 2006).

\section{Participants}

Two male twin sets (DZ and MZ) and their parents were purposively sampled from the corresponding author's regional hockey performance centre (as Head Coach) which is the fourth of six tiers in the National Governing Body (NGB) player pathway to junior national representation status. At the start of the study, the DZ twins were 15-years old, part of an intact family of five (with an older brother). Dizygotic twin 1 (DT1) was first-born. The MZ twins were 14-years old, part of an intact family of five (with an older sister). Monozygotic twin1 was first-born. Both sets were part of the U15 age group and trained together once every 2 weeks. Parents were full-time guardians with both sets of twins and all immediate 
family members lived together. Ethical approval was obtained by the university's ethics committee and signed informed consent/assent was provided by parents and athletes prior to data collection. Procedural approval was also obtained from the NGB.

\section{Procedure}

Due to the limited practical knowledge of siblings in TD, and the nature of the informal TD environment often obscured from view, qualitative observation (i.e., in depth information on a small number of individuals) allowed for the understanding of groups in their natural sporting environment, encouraging freely occurring behaviour to be maximized (Smith, 2018). As the primary researcher was a native of the environment (as Head Coach) it was possible for complete participation (Smith, 2018) observations to take place over 7 months, totalling $54 \mathrm{hr}$ of observation across training, classroom sessions, lunch periods, and competition days. This allowed for a more natural occurrence of behaviours to take place, and a true insiders' perspective as the researcher did not unnaturally alter the flow of interaction (Smith, 2018): importantly, such observation was a normal and accepted part of the training process, which was typically designed and overseen by the Head Coach. Therefore, the researcher participated within the context, recording the setting that was observed, the activities that took place and the people that participated on a reporting template (Smith, 2018). The recording template was then used to inform elements of the interview process with parents and siblings, as participants were provided with observed scenarios and asked to interpret them. In support of this perspective, Holder and Winter (2017) found that observations were adjunct to other assessment tools, such as interviews (i.e., for triangulation purposes), with Whyte (1984) suggesting observations can inform interviews, increase relevance, and allow participants to interpret events. Observations were collated from three coaches (the corresponding author, an advanced practitioner coach, and an ex-international coach) who regularly worked together as a team at the centre. The corresponding author has 4 
years of experience coaching at this level and a UKCC Level 2 qualification in hockey coaching. The remaining coaches had at least 10 years' experience and both hold a UKCC Level 3 qualification in hockey coaching. All coaches recorded observations at the end of each session. Observations took place during elements of the sessions when coaches were not actively coaching (e.g., warm-up, games, during tasks).

In light of these suggestions, single individual semi-structured interviews $(n=4)$ then took place with each athlete $\left(M_{\text {duration }}=37 \mathrm{~min}\right)$ and parent $\left(M_{\text {duration }}=41 \mathrm{~min}\right)$; recorded using a Dictaphone and stored electronically. These were conducted by the corresponding author and took place at a time and location identified by each family. Individual interviews took place privately, and all family members were interviewed consecutively. Three, overarching themes were used as a structure for the interview guides; exploring the relationship away from the pitch, interpretation of the observations and reference to previous studies (e.g., Blazo et al., 2014; Côté, 1999; Taylor et al., 2018). Individual interviews provided depth of questioning and personal information pertaining to the lived and observed experiences (Kaplowitz \& Hoehn, 2001), allowing the participant and researcher to co-construct research "truths" (Jones et al., 2006).

\section{Data Analysis}

Utilizing a codebook thematic analysis approach, potential themes were initially derived from previous studies exploring the sibling impact on TD (e.g., emotional interpersonal skills, separation, and skill development; Taylor et al., 2017), as well as inductively creating new categories in light of novel observations. This was deemed as the most appropriate approach to thematic analysis due to the novel and evolving understanding around siblings and TD (cf. Braun et al., 2019). This also allowed for the conceptualization of themes as domain summaries (Braun et al., 2019). During this process, connections between categories were explored, alongside application of a "revise, retest, revise" approach 
reflecting a pragmatic approach to handling data against what the literature highlights (Glaser $\&$ Strauss, 2017). Such analysis helped inform the subsequent semi-structured interview questions. Interviews were transcribed verbatim prior to conducting a codebook thematic analysis (Braun \& Clarke, 2006). Transcripts for parents and siblings within each family were converged for a more complete understanding of each case study (Baxter \& Jack, 2008). Codebook thematic analysis consisted of six stages using a qualitative software package (QSR NVIVO 10). Familiarization took place by the researchers immersing themselves in the content by reading and re-reading the data. Descriptive coding assigned initial raw data codes, before searching for subthemes through examination of these codes based on similar patterns of meaning. Next, subthemes were reviewed to determine an accurate picture of these data, illuminating the impact of twins on TD. Subthemes were grouped into distinct overarching themes that represent the impact of the relationship on TD (Braun \& Clarke, 2006). To assess the trustworthiness of the analysis, member reflection took place with each family member to validate the credibility of the data (Smith \& McGannon, 2017). This consisted of returning the results (i.e., themes and interpretations) of the interviews to participants, asking how accurate these were in terms of the interpretation presented, and requesting and noting any additional thoughts on the perceptions reported. Such an approach allowed for the controlling, and correcting, of subjective bias from the researcher, ensuring an accurate interpretation of knowledge (Smith \& McGannon, 2017).

\section{Results}

Following the data collection using observation and interview techniques described above, our codebook thematic analysis supported further development of themes from previous studies that focussed on age-gapped siblings; namely, interactional context, emotional interpersonal skills, rivalry, skill development, communication, and type of 
separation (Taylor et al., 2018; Taylor et al., 2017). Additionally, conflict and identity were novel higher-order themes (see Table 1). We now present these data by theme.

\section{***Table 1 here***}

\section{Interactional Context}

Participants acknowledged interactions within two main contexts; sport and other activities. Notably, the extent to which the twins interacted varied across the two cases, with the MZ twins revealing a greater desire to interact than the DZ twins. Exemplifying this typical interaction, monozygotic twin 2 (MT2) said: "We do a lot of things together, just in general really. So, we normally play a lot of sport outside together, many different sports, and we do some other activities together".

In the sport context, monozygotic twin 1 (MT1) explained that they "enjoy playing sports together", with the monozygotic father (MF) supporting this statement, adding: "The first one says, 'will you come with me onto the astro at school', and they'll do something together". MT2 highlighted that this provided further opportunity to practice: "It's useful to have him there because you can do certain things that someone on their own can't do". MF said that their interaction would not just be one-to-one: "As they grow into the group, they tend to move away from each other, then move back together". Coach observations appeared to support this tendency to move back together; for instance, during small group tactical discussions they would sit next to each other.

This interaction was less prominent in the DZ twins, as the dizygotic mother (DM) reflected: "Hockey is about the only thing they go and do together. They have an AstroTurf at their old primary school, and they did go down there and play together in that sport".

Dizygotic twin 2 (DT2) provided a little more breadth of sporting interaction; however, it was not portrayed as being a particularly sought-after choice: "We go swimming together, because there's no one else. So, we're alright together when we do things on holiday". 

said that they "generally spend a lot of time together, they do school work together", with MF describing how their wider social spheres were also well connected by having "a lot of friends outside of sport, and they tended to share a number of those friends".

For the DZ twins, however, DM highlighted that interactions were more frequent during periods of 'family time', such as “on holiday, when they don't have much choice, they will play together, and do things together". Furthermore, DT2 supported how organized family interactions brought them together: "We do things a lot with the family together".

\section{Emotional Interpersonal Skills}

This theme comprised of four subthemes; closeness, comfort, empathy, and support.

Again, the expression of this varied across the two case studies, with the MZ twins presenting a much more emotionally connected relationship than the DZ twins. MZ participants emphasized the closeness of the twin relationship, for example: "there's a very strong link there and that as individuals that relationship informs them, more than a non-twin" (MF). MM reiterated that the twins have "quite a special relationship". Reflecting this connection through sport, MT2 revealed their shared reactions to game results: "We normally feel the same things after a game or something, we both react to something the same". Behaviourally, it was observed that the twins warmed up together, MT1 interpreted this: "I would first go to [MT2] and that would settle me, and then I would build relationships with others". MM reinforced this behaviour: "You just grab your brother next to you, so yes I'd say that was a regular thing".

In the DZ twins, this closeness was far less evident; as summarized by one dizygotic twin (DT1): "We're not that close, no, but of course we're brothers so we like each other, but then we can get sick of each other". DT2 provided an insight into where the relationship sat 
within the family: "I've not got like a special connection with him just because we're twins. I don't think it's more important or don't value it as much as anyone else in the family".

These opinions notwithstanding, evidence of the subtheme comfort came from all four MZ participants. MT1 explained how this factor influenced his decision to select a warm-up partner, when saying: "I would probably go with him because I know him. I am most comfortable with him". MT2 expanded on this notion: "I prefer feeling like a twin because it is always there. Someone there to help you, and someone there you can talk to. You just have that security”. MM supported this by emphasizing the established nature of this bond: "They'll come back together quite quickly, back to being comfortable together". Comfort was less prominent in the DZ twins, with DM interpreting a coach observation around the twins alternating between being on the same team or playing against each other at training: "I think if they were on the same team then they would be more comfortable because they can trust each other". When talking about how they designed a session together in the classroom, DT1 suggested it worked as it was "something that was comfortable so you both sort of flow".

Empathy was revealed by MF and MT2. MF explained how "they want to do better than each other, but they don't want to see the other one sink, and they feel better when they're both doing well". MF gave an example of this:

If the focus is too much on one of them, the other one will notice. If we say, 'OK what do you do' and [MT2] was like 'oh I scored two goals', there will then be a pause, and then, 'but [MT1] did this really great pass or [MT1] did this other thing'.

MT2 described how he would feel if his twin did not do as well: "I would still feel for [MT1] and I wouldn't just go off and take that glory. I would try and help him”. Empathy was not identified in the DZ twins. 
Interpretations of the observations highlighted several examples of support within the

322 MZ twins. For example, during a small-sided game, one of the twins became frustrated with their own performance and this appeared to also impact on the other twin. MT1 provided the following interpretation: "I always would want him to perform well and be the best he can be, and always doing the best he can". Further observations included the appreciation of good passes to each other through clapping, verbal communication, and eye contact. MT1 suggested: "You are always trying to pick each other up". When asked about the perceived desire to look for each other with the ball, MT1 suggested: "I have a responsibility to always offer that option for him". Finally, MT2 explained how they would support each other: "If he is better at something, he wouldn't just keep on going himself, he would probably help me, and I would do the same thing”. However, seeking support was not exclusive between the twins, as MT2 also highlighted how they might go outside of their relationship for support: We would probably start talking to each other and then our dad would come in to the conversation and say, 'yes that is true', but if sometimes we were a bit worried, he would come in and say, 'don't be ... just play your best'.

In contrast, both DZ twins mentioned only occasional aspects of support. In the sporting context however, DT1 suggested that they did support their twin in some ways: "I would like him to succeed, but it doesn't bother me that much how he would do". DT2 also described how this support might appear: "Just maybe help him evaluate himself a bit better because a lot of people find it difficult to find the positives and negatives in themselves". DT1 highlighted that support was more often found outside of the twin relationship: "I'd say the coaches are probably the main people; and friends".

\section{Rivalry}


This theme was divided into two subthemes; competition and motivation. Across the

two case studies it appeared that rivalry played a different role. Within the MZ twins, competition was frequently discussed. MT1 emphasized this:

The aim is to have a better game than the other one, as it gives you bragging rights. Other people will go [MT1], [MT2] has got one up on you here, but I suppose we set ourselves a task, like trying to score more goals or get more assists.

MT2 agreed, explaining that: "I want to be better than him". During sessions the twins would often look over to each other when they were at different ends of the pitch. MT2 said: "If it's different ends of the pitch and we are doing the same drill I would try and beat what he is doing". MF stated in support of the competitive relationship between the twins: "That's probably the defining thing of their relationship, that competitive edge, in everything". For the DZ twins this competition appeared one-sided in the sporting context. DT1 said of a coach observation working together to design an aspect of the training session: "He is probably trying to think of something better than it. Yeah course he is, and I think he'll be more competitive than me to do better than me". However, outside of sport it was felt this competition was more consistent. DM believed that: "Being a twin adds that sense of competition at school". DT2 highlighted that this has always been the case: "Even in primary school we tried to get better grades than each other".

For the MZ twins, MT1 exemplified how their rivalry often motivated them:

If I see him having a good session and I am maybe not having a good session, then I focus on the second half, really trying to put it in so I could get to like what he was like in the first half.

MM also thought the rivalry was positive: "Not from a negative point of view, from a spurring each other on view". MT2 highlighted how various environments influenced this motivation: 
If we are at school and we are just with our mates and stuff it is not as serious, so we won't push each other as much. But if we are at a tournament and he is doing well I will definitely go out of my way to try and do something just as good. The role of motivation in the DZ twins was different. DT2 summarized this in sport: “I don't know why but I just want to be a bit better than him, even though I already am. I just want to be even better than him". However, when considering schoolwork, DT2 suggested that this motivation appeared equally: "If I start doing some revision he'll immediately go to his room and start doing some revision and vice-versa".

\section{Skill Development}

Analysis revealed that this appeared in the MZ twins as; mentoring and co-operation, but as co-operation and observation in the $\mathrm{DZ}$ twins. When considering the role of mentoring in the MZ relationship, MT1 gave the following account:

If I have done something wrong and I think he has done it quite well that session then I go, and I would ask him how did you do that? If they have performed a particular skill, how do you do that? And he would just help me with some points.

Although this was reciprocal, MT2 did not express an even balance of mentoring between the twins: "I feel like sometimes he mentors me a bit more, and I probably don't as much with him".

When considering co-operation, MT2 provided specific examples of how they would use their school pitch outside of training: "If he feels like he is not posting up very well then I will just hit balls at him or if I am not deflecting very well or hitting very well he will try and help me with that". They further emphasized how their co-operation tended to be positive: "Most of the time probably together and like working together. I think we work well together and we see that a couple of times in a few games we have played". 
Fewer links to co-operation appeared in the DZ twins. The dizygotic father (DF) gave an example of how purchasing a training aid to use at home developed some co-operation: "He did once do that and [DT1] sort of went out. I think they were trying to do some tackling". According to DM, co-operation appeared more in the school context: "They are cooperative when it comes to revision and schoolwork. They'll help each other by sharing". Within the DZ twins, DT1 suggested that they did get ideas from observing their twin during training sessions: "Say he's doing some ball work or dribbling I might try that or follow what he's doing". This observation did not require conversations: "I might just try it. I wouldn't talk to him about it". Observation was not expressed as apparent in the MZ twins.

\section{Communication}

This consisted of three subthemes; instruction, discussion and feedback. The role of these varied across the case studies. MZ twins reported more positively than the DZ twins. MT2 was the only participant to highlight the role which instruction played during practice: "If he sees I am doing something wrong he will say". Acknowledgement of this aspect of their relationship came when talking about whether his twin was the first person he would go to for help with his game: "Because he is playing in the same game, he is playing the same environment as me, and if he was doing better, then I definitely would ask him ... he would tell me how to get better and that".

Within the DZ twins, this instruction was a one-way process, from DT2 to DT1. This was exemplified by a coach observation where the twins were defending together in a training session and DT2 was very vocal: "I just put him in a position where he could do the best he could". DT1 suggested he was fine with this: "I feel better because I don't have to make the decision on my own, and I've got someone there telling me what to do". DF explained why this might happen: "He [DT1] is less confident ... and in that situation [DT2]'s confidence trumps [DT1]'s lack of confidence, and therefore he responds". 
highlighting: "They want to discuss something, they want to talk about something, they want to see what the other one feels about that". MT2 provided a general view of how this might appear: "It is more like both sides, going from both sides and helping each other instead of the other one telling the other one what to do". MT1 gave an example of how this discussion could take place during car journeys after competition: "If they had gone well, we would just be talking about the games". MM reinforced this: "The journey home was an analysis of how they played". MT1 specifically mentioned: "We wouldn't normally talk if it had gone well ... but if it had gone negatively then we talk to each other, but it doesn't get negative".

In the DZ twins there was evidence of discussion around how they played. DT2 commented on observations made by the coach that the twins did not seem too concerned with how the other was doing when on the pitch: "I'd ask him [afterwards] how did you get on with that, he'll respond, and we'll have a chat about it'. On the way home from competition DT1 said such discussion would rarely be in detail: "We were talking about the game. I don't think we talked much about how we played and improvement”.

Feedback was identified in the MZ case. MF talked about how the twins validated each other: "Part of that validation is internally. I think as they learn it's not just we won the game. They validate each other". During the classroom session on a training day the players were given a self-evaluation and goal setting task, with the twins doing this together: That would probably be a common question between us and I would say do you think I am a 7, what do you think of that? And you're probably a 7 and say 'oh yes no that is what I was thinking along those lines' but normally we are quite in the same mindset. It is like that would just help us with getting an accurate interpretation. (MT1) 
MT1 acknowledged that feedback also came from outside of the twin relationship during and after training and competition: "If anyone wants to say something it would probably be mum or dad, or a coach or another player".

In the DZ twins, feedback had limited use. During a classroom session the coach observed them sat together doing some performance evaluation. When asked about this DT2 shared: "We just like check, just say what are you writing, and criticize it or say how I could get better maybe". DF also suggested this might be negative if they had done something good during a game: "[DT1] would normally have a sting in the tail, like 'oh there was a deflection there, that is why it went in"”.

\section{Conflict}

Conflict appeared to be more prevalent in the DZ twins than the MZ twins. This was represented by the subthemes of arguments and frustration in the MZ twins, and arguments, frustration, and criticism in the DZ twins. MT2 and MF highlighted how arguments might occur, across contexts, between the MZ twins. MT2 declared: "We obviously do fight sometimes". MF gave an example of how this might appear in the wider context of their interaction: "The schoolwork they do together. They fallout about the nature of how they are going to do it". MT2 outlined their feelings around falling out: "I would never want to have an argument, but then if we do have one that would happen".

There was also some evidence of arguments between the DZ twins. When asked if arguments do occur, DT2 answered: "Yes, quite a bit, but we just deal with it really". DF provided some further insight into why such arguments might occur: "The way it is delivered means that it is not well received, so [DT1] might say 'you are a bit bossy on the field, can you stop shouting orders' and [DT2] says 'you are always out of position you'”.

Both MZ twins identified the frustration that may appear. MT1 gave an example of how this might happen in the sporting context: 
I was like I will give you the ball, and he is thinking he was running in to the space for me to throw it down the line but I wasn't and sometimes we expect more ... and not that he doesn't deliver it but we just are expecting different things in a similar situation and then it becomes negative like why did you do this?

MT2 emphasized the impact this frustration can have on their interactions: "One of us becomes annoyed by that, and then we just split up and do our own things". Frustration was mentioned by both DZ twins. DT2 was frustrated with the way DT1 approached sport: “I just don't think it's the right way. I just don't see the point in training to not compete. That's just something I don't think is worth it". When summarizing their relationship DT1 suggested that because they do quite a lot together across different contexts that they can get frustrated: "That can mean like we get a bit fed up with each other".

In contrast, Criticism was a subtheme that emerged only with the DZ twins. DT2 was honest with the assessment of DT1's sporting ability: “He knows I don't think he's that good. I put him down a bit sometimes". When asked how this might appear, DT2 suggested: "Just through my actions, I sometimes say it at home”. DF gave further detail about how this might happen in the car on the way home from competition: "In the car going back I said how that game was, did you enjoy it? And [DT1] might say, 'oh [DT2] was shocking in defending situations, he let the ball go through', and then [DT2] would counter that".

\section{Type of Separation}

Separation is explored across both cases through the subthemes of sport specific and general types. Sport specific separation was mentioned by both MZ twins, with MT2 suggesting that their training environment would impact on this: "If it is different ends of the pitch and we are doing different drills I probably wouldn't think about him, I would focus on my own play". This supported MT2's interpretation of a coach observation where they focussed on their own skill execution during an activity: "I probably focus a bit more on my 
own game". MT2 also suggested that they were starting to deliberately separate, when discussing their approach to fitness training at the start of a session: "Last night we didn't run together because I thought that might help a bit more to try and run with someone else". When practising for hockey at home DT2 provided the following example in relation to sport specific separation:

I get [DT1] to try and help me, but he's very reluctant to do it. So, I'd say because I want to practice my passing really close a few metres apart, he's a bit reluctant to do it. He wants to go and do something else. Not hockey related.

During sessions it was observed that they would not always warm up together. DM provided the following possible explanation: “They are more individuals; they don't see each other as a unit together. It would be perfectly normal for them to do their own thing”. DT1 supported this: "In training we would go with people that are around our level". In relation to general separation, in the MZ case, MT2 emphasized at times their interactions, when it came to homework, "would start off well and it would sometimes just break up, and we would stop working together". MF provided some thought around the longevity of such separation:

There's a catharsis and there's a resistance to separating completely and going off and doing it on their own. We can say separate and work on your own. They'll do that for a short period of time before suddenly they're back together and we say come on you were arguing why don't you stay separated. No, we're alright now we've figured it out.

In the DZ case, the emphasis on general separation was similarly to that of sport specific separation. DF summarized this: "They have their own little spaces of influence; friendship groups, they get invited to different parties or people's houses ... They seem to be 
happy enough with that". When discussing this DT1 said: "We don't see each other at school, and then when we come back home we're doing our own stuff with work".

\section{Identity}

The theme identity was only apparent with the DZ twins; producing the subthemes of acceptance and characteristics. Acceptance was identified by DT1 who perceived their twin to be better at sport: "I used to think I was a similar standard at hockey to him or maybe a bit better because we picked that up late. He did badminton before I did, so I knew he was better from the beginning". Further evidence of this came from DM who interpreted the coach observation of DT2 instructing DT1 through an activity: "That's not unusual, that's a normal role for them. I think [DT1] is accepting that he bows to [DT2]". Further acceptance of identity was linked to their rivalry: "He's more competitive, so his hockey is going to a higher level, and in badminton he's getting to a higher level" (DT1).

All alluded to the twins having different characteristics, with DF summarizing this: They are definitely not inseparable, and they are different people ... They are not identical in any way. [DT2] would be much more openly driven and happy to talk about that fact ... [DT1] is more reserved, he is more relaxed as well.

DT2 provided insight into these differences in a school context: "At school we wanted to be separated. We want to be different people and have different groups of friends, and not be like the same person, just because we're twins, and we like to have different birthdays".

\section{Discussion}

This study aimed to extend research addressing the nature of sibling interactions during $\mathrm{TD}$, by observing a set of $\mathrm{MZ}$ and $\mathrm{DZ}$ twins within the same TD environment across an extended duration. Identified themes support evidence for the wider sibling relationship's impact on TD, through interactional context, emotional interpersonal skills, rivalry, skill development, communication, and type of separation (Blazo et al., 2014; Davis \& Meyer, 

addition, conflict was apparent in both twin sets, and identity in the DZ twins, highlighting the difference between sibling types more broadly, and twin types more specifically; at least in these specific pairs. These findings add support to the validity of themes in the sibling literature and, therefore, continue to reaffirm our understanding of the possible role that siblings may play in TD.

Of course, as research into different types of sibling relationship within TD environments increases, it is unsurprising that data will emerge to support a complex and highly individualized perspective (cf. Taylor et al., 2018). As such, the focus of this discussion section will aim to explain the pertinence of our findings as an exemplar for coaches when addressing athlete case studies. Consider identity, a theme only evident for the DZ twins. There was an acceptance that they were different and that they had different characteristics (see Table 1.). This would suggest the DZ twins are going through a process of deidentification, where siblings look to establish a unique identity (McHale et al., 2012). Feinberg and Hetherington (2000) highlight that siblings who are similar in age and gender (i.e., male twin set) are more likely to differentiate from each other. Such a dynamic, leads to siblings choosing to participate in different activities which, increases separation. Furthermore, Whiteman et al. (2007) recognize that deidentifying with your sibling can be a mechanism to reduce competition and minimize comparison and rivalry, as well as reducing levels of closeness .

From a coaching perspective, as this process takes place over time, it is reasonable to suggest that there are benefits within the TDE. Part of the deidentification process is learning from your sibling with the aim of developing individual athletic identities (e.g., they slow down at the end of a run, so I'm going to speed up; Whiteman et al., 2007). Take the statement made by DT2 regarding rivalry; "I just want to be even better than him". Athletes, 
in a TDE, who self-regulate may improve performance faster and perform more successfully which increases their chance of selection (Toering et al., 2009). Self-regulated learners are metacognitively, behaviourally and motivationally proactive when it comes to their own learning process, leading to high levels of effort and persistence during learning opportunities (Zimmerman, 2006). Using metacognitive strategies such as planning (e.g., setting goals), self-monitoring (during the task), evaluation (i.e., mentally evaluate against their goals considering process and outcome), and reflection across the process, self-regulated learners are more effective at acquiring skills and knowledge over time than athletes that are not (Toering et al., 2009). Such individuals know how to improve and select appropriate regulatory strategies when they identify a gap in their skillset which increases the chance of optimizing practice into competition (Toering et al., 2009). Notably, the development of selfregulated learners requires the support of significant others as the athlete develops the skills required (Collins \& MacNamara, 2018). In this case, due to the increased permeability of the DZ twin subsystem boundaries (Minuchin, 1974) it is likely that such support will come from a coach, with Toering et al. (2009) suggesting that coaches can emphasize the skills required (e.g., reflection) in practice and competition by encouraging players to reflect on their performance in order to improve, instead of telling athletes what they need to work on. In contrast, the MZ data reveals a process of modelling taking place (e.g., Interactional Context: see Table 1.). Whiteman et al. (2013) describe modelling as a social mechanism driving observed similarity in sibling outcomes, leading to siblings following a similar life course while using each other as a progressive reference point. Siblings who engage in the modelling process often have a warmer relationship, and imitate behaviour by practicing and receiving feedback (Bandura, 1977). Bandura (1977) highlights that modelling is more likely to take place when siblings are more similar (i.e., they are a fraternal 
twin set), with Watzlawik (2009) recognizing that MZ twins derive more self-esteem and self-confidence from their sibling relationship than DZ and age-gapped siblings.

Referring to our earlier discussion around self-regulated learning, it is important to note the role of motivation in helping learners transform their mental skills into performance skills through self-directed processes (Toering et al., 2011). Zimmerman (2006) identified that motivational beliefs (e.g., self-efficacy; Bandura, 1977) and outcome variables (e.g., effort) were positively associated with self-regulation. Consequently, there is a relationship between self-regulation and intrinsic (i.e., activity is meaningful) versus extrinsic (i.e., a means to an end) motivation, with an athlete's desire to achieve being dependent on their perception of competence and control (cf. Toering et al., 2011). With the MZ twins having an enmeshed subsystem (Minuchin, 1974) there are possible benefits for coaches when considering the role of each MZ twin in developing self-regulation. For example, siblings can drive self-regulation through giving their twin greater responsibility for aspects of training and encourage feedback and reflection on performance (Collins \& MacNamara, 2018). This process of support and co-operation can help an athlete move from dependence to interdependence and encourage them to seek support from others when needed. Furthermore, in order to maintain appropriate intrinsic motivation, it is important that an athlete has many opportunities to experience and practice with capable peers, in this case their twin, as modelling (e.g., appropriate behaviours) and scaffolding (e.g., support to develop competence) can take place (Collins \& MacNamara, 2018). These are crucial skillsets as athletes navigate the usually nonlinear TD pathway (Collins \& MacNamara, 2012). Of course, early stage research such as this study is not without its limitations. Smith (2018) suggests that the way the researcher may or may not interact with participants can have significant implications to the research. Due to the changing nature of the coaches' role to coach-researcher in the environment, it was not always possible to interact and observe the 
twin sets without a risk that this would influence their behavior as a result of the latter.

Furthermore, we highlighted earlier the importance and significance of adopting an approach that illuminates smaller cases in detail (cf. Normand, 2016), however, future work should look to test these ideas, and those revealed within other sibling research, with a larger sample size (Crouch \& McKenzie, 2006).

\section{Implications for Coaching Practice}

Such discussion highlights the need for coaches to adopt an "it depends" view when considering the use of siblings in TD. This may contradict the desire of some to be provided with a generalized approach within TD. Importantly, however, reducing the use of siblings to a simplistic/formulaic level is at epistemological odds with the complex dynamics of the sibling relationship and TD environment (Cruickshank \& Collins, 2016). Consequently, the use of PJDM, considering the context (i.e., TD environment) and the available options for taking action (i.e., the specific characteristics of the individual sibling relationship) is essential in identifying if a sibling may be able to support TD. Importantly, Cruickshank and Collins explain that this should involve reflective questioning from coaches concerning the following; when and when not to use the relationship to support TD (e.g., pre-season or midseason), which sibling relationships would or would not add value, where (and where not) to use the relationship (e.g., formally or informally), and crucially (cf. Martindale \& Collins, 2012), why (and why not). As Cruickshank and Collins (2016, p. 1201) suggest, looking for "neat and tidy" competencies (e.g., all siblings are competitive), over harder to define cognitive skills that underpin expertise (e.g., I have identified that sibling Set A are highly competitive, but sibling Set B are co-operative), will not allow us to optimally understand, explain, and support effective TD.

In light of these considerations, it is important that coaches consider how they can acquire the appropriate knowledge and understanding of an individual sibling relationship in 
order to ascertain its benefit to TD. Therefore, we support and advocate an extension of practice-based inquiry (e.g., observations; Holder \& Winter, 2017) when combined with athlete-coach/parent-coach conversations to reduce the limitations that the coaching environment places on the use of observations (e.g., time with individual players at the expense of the whole team). Observational methods allow the coach to gain a holistic perspective of those under study (i.e., observing all aspects of the sibling relationship; Smith, 2018) increasing the opportunity for insight into the interdisciplinarity that may take place. Such an approach reflects the bio-psycho-social requirements of TD due to its complexity (Collins et al., 2012) and supports further exploration of the bio-psycho-social impact siblings can have on TD (Taylor et al., 2018). Furthermore, and in accordance with Taylor et al.'s (2018), consideration of the individualized and complex nature of the sibling relationships (i.e., differences between siblings across families), observations allow freely occurring behaviour to take place within a less manipulated environment, creating opportunities for relationship dynamics that truly exist to appear (cf. Smith, 2018) allowing coaches to gain a clearer understanding of the individual sibling dyad. With such observations more meaningfully guiding and informing athlete-coach/parent-coach conversations. Finally, consideration of interactions between coaches and other specialist staff (e.g., sport psychologists, player liaison officers) can support the development of knowledge, thereby increasing the opportunity to develop and/or support interventions with optimal benefits to TD. Moving forwards, further testing and tracking of possible interventions informed by such a pragmatic approach would continue to advance knowledge of the role of siblings in TD.

\section{Conclusion}

This study has continued to build insight around the impact of siblings on TD in sport, through the exploration of twins within a talent pathway. While previously identified themes were verified as present in this context (i.e., each case study), new ones have added to this 
664 growing body of research. The practice-based approach has illuminated a plausible method 665 for coaches considering the use of this relationship within their practice, and further 666 illuminated the accuracy of parent knowledge and observation.

667 Overall, this study continues to advocate the complexity and individualized nature of 668 the sibling subsystem, alongside the influence of twin type on their relationship when 669 considering the impact on TD. Further examples of FST highlighted the variation in twin type 670 relationship, demonstrating the boundary dynamics that can impact upon the outcomes of TD 671 within, and outside of the subsystem. Findings from this study would also be beneficial to 672 wider family units as many families have siblings that are close in age, are constantly 673 compared, or look similar (Noble et al., 2017). Finally, we suggest that addressing the 674 practical consideration of the impact these themes have on TD would allow for the 675 opportunity to explore the effectiveness of their use in TDEs. 


\section{References}

Abbott, A., Button, C., Pepping, G. J., \& Collins, D. (2005). Unnatural selection: Talent identification and development in sport. Nonlinear Dynamics, Psychology, and Life Sciences, 9, 61-88.

Abraham, A., Collins, D., \& Martindale, R. (2006). The coaching schematic: validation through expert coach consensus. Journal of Sports Sciences, 24, 549-564. doi:10.1080/02640410500189173

Ackerman, P. L. (2014). Nonsense, common sense, and science of expert performance: Talent and individual differences. Intelligence, 45, 6-17. doi:10.1016/j.intell.2013.04.009

Ainslie, R. (1997). The psychology of twinship. Northvale, NJ: Jason Aronson.

Bacon, K. (2010). Twins in society: Parents, bodies, space and talk. Basingstoke: Palgrave Macmillan UK.

Bailey, R., Collins, D., Ford, P. A., MacNamara, Á., Toms, M. R., \& Pearce, G. (2010). Participant development in sport: An academic review. Leeds: Sports Coach UK.

Baker, J., \& Horton, S. (2004). A review of primary and secondary influences on sport expertise. High Ability Studies, 15, 211-228. doi:10.1080/1359813042000314781

Bandura, A. (1977). Social learning theory. Englewood Cliffs, NJ: Prentice Hall.

Baxter, P., \& Jack, S. (2008). Qualitative case study methodology: Study design and implementation for novice researchers. The Qualitative Report, 13, 544-559.

Blazo, J. A., Czech, D. R., Carson, S., \& Dees, W. (2014). A qualitative investigation of the sibling sport achievement experience. The Sport Psychologist, 28, 36-47.

Blazo, J. A., \& Smith, A. L. (2018). A systematic review of siblings and physical activity experiences. International Review of Sport and Exercise Psychology, 11, 122-159. doi:10.1080/1750984X.2016.1229355 
Bowen, M. (1978). Family therapy in clinical practice. New York: Jason Aronson.

Braun, V., \& Clarke, V. (2006). Using thematic analysis in psychology. Qualitative Research in Psychology, 3, 77-101. doi:10.1191/1478088706qp063oa

Braun, V., Clarke, V., Hayfield, N., \& Terry, G. (2019). Thematic analysis. In P. Liamputtong (Ed.), Handbook of research methods in health social sciences (pp. 843860). Singapore: Springer Singapore.

Bryant, A. (2009). Grounded theory and pragmatism: The curious case of Anselm Strauss. Forum: Qualitative Social Research, 10, Art. 2. doi:10.17169/fqs-10.3.1358

Collins, D., Bailey, R., Ford, P. A., MacNamara, Á., Toms, M., \& Pearce, G. (2012). Three worlds: New directions in participant development in sport and physical activity. Sport, Education and Society, 17, 225-243. doi:10.1080/13573322.2011.607951

Collins, D., Burke, V., Martindale, A., \& Cruickshank, A. (2015). The illusion of competency versus the desirability of expertise: Seeking a common standard for support professions in sport. Sports Medicine, 45, 1-7. doi:10.1007/s40279-014-0251-1

Collins, D., \& MacNamara, Á. (2012). The rocky road to the top: Why talent needs trauma. Sports Medicine, 42, 907-914. doi:10.2165/11635140-000000000-00000

Collins, D., \& MacNamara, Á. (2018). Talent development: A practitioners guide. Oxon: Routledge.

Collins, D., MacNamara, Á., \& McCarthy, N. (2016). Super champions, champions and almosts: Important differences and commonalities on the rocky road. Frontiers in Psychology, 6, 2009. doi:10.3389/fpsyg.2015.02009

Collins, L., \& Collins, D. (2015). Integration of professional judgement and decision-making in high-level adventure sports coaching practice. Journal of Sports Sciences, 33, 622633. doi:10.1080/02640414.2014.953980 
Côté, J. (1999). The influence of the family in the development of talent in sport. The Sport Psychologist, 13, 395-417.

Crouch, M., \& McKenzie, H. (2006). The logic of small samples in interview-based qualitative research. Social Science Information, 45, 483-499. doi:10.1177/0539018406069584

Cruickshank, A., \& Collins, D. (2016). Advancing leadership in sport: Time to take off the blinkers? Sports Medicine, 46, 1199-1204. doi:10.1007/s40279-016-0513-1

Davids, K., \& Baker, J. (2007). Genes, environment and sport performance. Sports Medicine, 37, 961-980. doi:10.2165/00007256-200737110-00004

Davis, N. W., \& Meyer, B. B. (2008). When sibling becomes competitor: A qualitative investigation of same-sex sibling competition in elite sport. Journal of Applied Sport Psychology, 20, 220-235. doi:10.1080/10413200701864817

Feinberg, M. E., \& Hetherington, E. M. (2000). Sibling differentiation in adolescence: Implications for behavioral genetic theory. Child Development, 71, 1512-1524.

Felson, J. (2014). What can we learn from twin studies? A comprehensive evaluation of the equal environments assumption. Social Science Research, 43, 184-199. doi:10.1016/j.ssresearch.2013.10.004

Flyvbjerg, B. (2006). Five misunderstandings about case-study research. Qualitative Inquiry, 12, 219-245. doi:10.1177/1077800405284363

Fortuna, K., Goldner, I., \& Knafo, A. (2010). Twin relationships: A comparison across monozygotic twins, dizygotic twins, and nontwin siblings in early childhood. Family Science, 1, 205-211. doi:10.1080/19424620.2010.569367

Galton, F. (1875). The history of twins, as a criterion of the relative powers of nature and nurture. Fraser's Magazine, 12, 566-576. 
Giacobbi, P. R., Poczwardowski, A., \& Hager, P. (2005). A pragmatic research philosophy for applied sport psychology. The Sport Psychologist, 19, 18-31.

Glaser, B., \& Strauss, A. (2017). Discovery of grounded theory: Strategies for qualitative research. Oxon: Routledge.

Haworth, C. M., Davis, O. S., \& Plomin, R. (2013). Twins Early Development Study (TEDS): A genetically sensitive investigation of cognitive and behavioral development from childhood to young adulthood. Twin Research and Human Genetics, 16, 117-125. doi:10.1017/thg.2012.91

Holder, T., \& Winter, S. (2017). Experienced practitioners' use of observation in applied sport psychology. Sport, Exercise, and Performance Psychology, 6, 6-19. doi:10.1037/spy0000072

Huguet, P., Carlier, M., Dolan, C. V., de Geus, E. J., \& Boomsma, D. I. (2017). Social comparison orientation in monozygotic and dizygotic twins. Twin Research and Human Genetics, 20, 550-557. doi:10.1017/thg.2017.61

Jones, S., Torres, V., \& Arminio, J. (2006). Negotiating the complexities of qualitative research in higher education: Fundamental elements and issues. New York: Routledge.

Kaplowitz, M. D., \& Hoehn, J. P. (2001). Do focus group and individual interviews reveal the same information for natural resource valuation? Ecological Economics, 36, 237247. doi:10.1016/S0921-8009(00)00226-3

Kinugasa, T. (2013). The application of single-case research designs to study elite athletes' conditioning: An update. Journal of Applied Sport Psychology, 25, 157-166. doi:10.1080/10413200.2012.709578 
Knight, C. (2017). Family influences on talent development in sport. In J. Baker, S. Cobley, \& J. Shorer (Eds.), Routledge handbook of talent development and identification in sport (pp. 181-191). Oxon: Routledge.

Lytton, H. (1980). Parent-child interaction: The socialization process observed in twin and singleton families. New York: Plenum Press.

Martindale, A., \& Collins, D. (2012). A professional judgment and decision making case study: Reflection-in-action research. The Sport Psychologist, 26, 500-518. doi:10.1123/tsp.26.4.500

May, T. (2011). Social research: Issues, methods and process. Maidenhead: McGraw-Hill.

McHale, S. M., Updegraff, K. A., \& Whiteman, S. D. (2012). Sibling relationships and influences in childhood and adolescence. Journal of Marriage and Family, 74, 913930. doi:10.1111/j.1741-3737.2012.01011.x

Minuchin, S. (1974). Families and family therapy. Cambridge, MA: Harvard University Press.

Morgan, D. L. (2007). Paradigms lost and pragmatism regained; methodological implications of combining qualitative and quantitative methods. Journal of Mixed Methods Research, 1, 48-76.

Nelson, K., \& Strachan, L. (2017). Friend, foe, or both? A retrospective exploration of sibling relationships in elite youth sport. International Journal of Sports Science \& Coaching, 12, 207-218. doi:10.1177/1747954117694923

Noble, N., Bradley, L., Parr, G., \& Duemer, L. (2017). Fostering twins’ identity development: A family issue. The Family Journal, 25, 345-350.

Normand, M. P. (2016). Less is more: Psychologists can learn more by studying fewer people. Frontiers in Psychology, 7, 934. doi:10.3389/fpsyg.2016.00934 
ONS. (2016). Birth characteristics in England and Wales: 2016. Retrieved from https://www.ons.gov.uk/

Phillips, E., Davids, K., Renshaw, I., \& Portus, M. (2010). Expert performance in sport and the dynamics of talent development. Sports Medicine, 40, 271-283. doi:10.2165/11319430-000000000-00000

Segal, N. (2000). Entwined lives: Twins and what they tell us about human behavior. New York: Plume.

Smith, B., \& McGannon, K. R. (2017). Developing rigor in qualitative research: Problems and opportunities within sport and exercise psychology. International Review of Sport and Exercise Psychology, 11, 1-21. doi:10.1080/1750984X.2017.1317357

Smith, M. F. (2018). Research methods in sport. London: Sage.

Tancredy, C. M., \& Fraley, R. C. (2006). The nature of adult twin relationships: an attachment-theoretical perspective. J Pers Soc Psychol, 90, 78-93. doi:10.1037/00223514.90 .1 .78

Taylor, R. D., Carson, H. J., \& Collins, D. (2018). The impact of siblings during talent development: A longitudinal examination in sport. Journal of Applied Sport Psychology, 30, 272-287. doi:10.1080/10413200.2017.1384938

Taylor, R. D., \& Collins, D. (2015). Reviewing the family as a stakeholder in talent development: Is it undervalued? Quest, 67, 330-343. doi:10.1080/00336297.2015.1050747

Taylor, R. D., Collins, D., \& Carson, H. J. (2017). Sibling interaction as a facilitator for talent development in sport. International Journal of Sports Science \& Coaching, 12, 219 230. doi:10.1177/1747954117694926

Toering, T. T., Elferink-Gemser, M. T., Jordet, G., Jorna, C., Pepping, G. J., \& Visscher, C. (2011). Self-regulation of practice behavior among elite youth soccer players: An 
exploratory observation study. Journal of Applied Sport Psychology, 23, 110-128. doi:10.1080/10413200.2010.534544

Toering, T. T., Elferink-Gemser, M. T., Jordet, G., \& Visscher, C. (2009). Self-regulation and performance level of elite and non-elite youth soccer players. Journal of Sports Sciences, 27, 1509-1517. doi:10.1080/02640410903369919

Trussell, D. (2014). Contradictory aspects of organized youth sport: Challenging and fostering sibling relationships and participation experiences. Youth \& Society, 46, 801-818. doi:10.1177/0044118X12453058

Watzlawik, M. (2009). The perception of similarities and differences among adolescent siblings: Identification and deidentification of twins and nontwins. Journal of Adolescent Research, 24, 561-578. doi:10.1177/0743558409338301

Whiteman, S. D., Jensen, A. C., \& Maggs, J. L. (2013). Similarities in adolescent siblings' substance use: testing competing pathways of influence. J Stud Alcohol Drugs, 74, 104-113. doi:10.15288/jsad.2013.74.104

Whiteman, S. D., McHale, S. M., \& Crouter, A. C. (2007). Competing processes of sibling influence: Observational learning and sibling deidentification. Social Development, 16, 642-661. doi:10.1111/j.1467-9507.2007.00409.x

Whyte, W. F. (1984). Learning from the field: A guide from experience. London: Sage.

Winter, S., \& Collins, D. (2015). Why do we do, what we do? Journal of Applied Sport Psychology, 27, 35-51. doi:10.1080/10413200.2014.941511

Zimmerman, B. J. (2006). Development and adaption of expertise: The role of self-regulatory processes and beliefs. In K. A. Ericsson, N. Charness, P. J. Feltovich, \& R. R. Hoffman (Eds.), The Cambridge handbook of expertise and expert performance (pp. 705--722). New York: Cambridge University Press. 
Table 1. Case-based representation of potential mechanisms that support TD.

\begin{tabular}{|c|c|c|}
\hline $\begin{array}{l}\text { Monozygotic twins }(M)-\text { Exemplar raw } \\
\text { data codes } \\
M=\text { Mother } / \mathrm{F}=\text { Father } / \mathrm{T}=\text { Twin }\end{array}$ & $\begin{array}{l}\text { Overarching } \\
\text { themes } \\
\text { Subthemes }\end{array}$ & $\begin{array}{l}\text { Dizygotic twins }(D)-\text { Exemplar raw } \\
\text { data codes } \\
M=\text { Mother } / F=\text { Father } / T=\text { Twin }\end{array}$ \\
\hline & $\begin{array}{l}\text { Interactional } \\
\text { context }\end{array}$ & \\
\hline $\begin{array}{l}\text { "Then mostly we just play sport with each } \\
\text { other" (MT2) } \\
\text { "We enjoy playing sports together" (MT1) }\end{array}$ & Sport & $\begin{array}{l}\text { "We go swimming together, because } \\
\text { there is no one else" (DT2) } \\
\text { "We do tennis and badminton" (DT1) }\end{array}$ \\
\hline $\begin{array}{l}\text { "We do a lot of things together just in } \\
\text { general" (MT2) } \\
\text { "They tended to share a number of those } \\
\text { friends" (MF) }\end{array}$ & Other activities & $\begin{array}{l}\text { "We do a lot of things together like more } \\
\text { school work" (DT2) } \\
\text { "We go on the PlayStation, do that kind } \\
\text { of stuff" (DT1) }\end{array}$ \\
\hline & $\begin{array}{l}\text { Emotional } \\
\text { interpersonal } \\
\text { skills }\end{array}$ & \\
\hline $\begin{array}{l}\text { "We both react to something the same" } \\
\text { (MT2) } \\
\text { "Day to day they are incredibly close" (MF) }\end{array}$ & Closeness & $\begin{array}{l}\text { "We get on well when we're not with } \\
\text { other people" (DT1) } \\
\text { "Yeah we get on all right" (DT2) }\end{array}$ \\
\hline $\begin{array}{l}\text { "Probably first go to him, and that would } \\
\text { probably settle me" (MT1) } \\
\text { "They'll come back together quickly" (MM) }\end{array}$ & Comfort & $\begin{array}{l}\text { "I think there is a comfort in the fact that } \\
\text { they are both always around" (DF) } \\
\text { "Comfortable so you both flow" (DT1) }\end{array}$ \\
\hline $\begin{array}{l}\text { "I would still feel for him" (MT2) } \\
\text { "They don't try and rub the others one's } \\
\text { nose in it" (MF) }\end{array}$ & Empathy & \\
\hline $\begin{array}{l}\text { "When we're on good terms we'll help each } \\
\text { other" (MT2) } \\
\text { "I would always want him to perform well } \\
\text { and be the best" (MT1) }\end{array}$ & Support & $\begin{array}{l}\text { "I would like him to succeed but it } \\
\text { doesn't bother me that much" (DT1) } \\
\text { "It's just about me really. Shouldn't } \\
\text { really be worrying about him" (DT2) }\end{array}$ \\
\hline & Rivalry & \\
\hline $\begin{array}{l}\text { "I want to do as well as he is doing" (MT2) } \\
\text { "They're just very competitive about } \\
\text { everything" (MF) }\end{array}$ & Competition & $\begin{array}{l}\text { "There seems to be a little bit of sibling } \\
\text { rivalry in the social sense" (DF) } \\
\text { "We would be competitive" (DT1) }\end{array}$ \\
\hline $\begin{array}{l}\text { "Just pushing each other" (MT2) } \\
\text { "Wanting to learn is driven by each other" } \\
\text { (MF) }\end{array}$ & Motivation & $\begin{array}{l}\text { "A higher standard and that probably } \\
\text { motivates him" (DM) } \\
\text { "I think it definitely pushes them" (DM) }\end{array}$ \\
\hline & $\begin{array}{l}\text { Skill } \\
\text { development }\end{array}$ & \\
\hline $\begin{array}{l}\text { "Feel like he mentors me a bit more" (MT2) } \\
\text { "He'd just help me with some points" (MT1) }\end{array}$ & Mentoring & \\
\hline $\begin{array}{l}\text { "We go on the astro and try and resolve it" } \\
\text { (MT2) } \\
\text { "There's competition going on, yet they are } \\
\text { doing it together" (MF) }\end{array}$ & Co-operation & $\begin{array}{l}\text { "I think he did once do that. I think they } \\
\text { were trying to do some tackling" (DF) } \\
\text { "We've been doing hockey a bit, but not } \\
\text { that often" (DT1) }\end{array}$ \\
\hline
\end{tabular}


"I would ask him and he'd tell me how to get better (MT2)

"In the game it's quite instructive, he will definitely tell me what to do" (MT2)

"After a game we talk about that" (MT2)

"Discuss how they played, what the selectors were perhaps looking for" (MM)

"Go up to him and give him the praise he deserves" (MT2)

"More likely to talk about what the other one did" (MF)

"If I say something he disagrees with then that will cause an argument" (MT2)

"Sometimes it's the fact it's their favourite person to argue with" (MF)

"Maybe I was playing well and it brought me down" (MT1)

"Frustration, anger towards him.

Annoyance that he's not seeing what I see" (MT2)

“Just be like, I don't need you" (MT2)

"I would always try and separate myself if we are doing the same drills (MT1)

"We just split up, do our own thing" (MT2) "Been spending too much time together and just need to split up" (MM)

\begin{tabular}{|c|c|}
\hline Observation & $\begin{array}{l}\text { "Say he's doing some ball work or some } \\
\text { dribbling I might try that or follow what } \\
\text { he is doing" (DT1) } \\
\text { "I wouldn't really look at what he is } \\
\text { doing; I wouldn't be that bothered. } \\
\text { Might take ideas from him" (DT1) }\end{array}$ \\
\hline \multicolumn{2}{|l|}{ Communication } \\
\hline Instruction & $\begin{array}{l}\text { "Yeah I would listen to him and listen to } \\
\text { anyone that is better than me, so I'd just } \\
\text { follow them" (DT1) } \\
\text { "I'll give him some advice and he just } \\
\text { won't really take it into account" (DT2) }\end{array}$ \\
\hline Discussion & $\begin{array}{l}\text { "If there is any discussion it doesn't take } \\
\text { very long" (DF) } \\
\text { "Maybe talk about the game with" } \\
\text { (DT2) }\end{array}$ \\
\hline Feedback & $\begin{array}{l}\text { "I'd say you did this well you might } \\
\text { have done this badly" (DT2) } \\
\text { "Occasionally he might say oh [T2] } \\
\text { scored a good goal" (DF) }\end{array}$ \\
\hline \multicolumn{2}{|l|}{ Conflict } \\
\hline Arguments & $\begin{array}{l}\text { "I'll just say you're not that great, and } \\
\text { he'll just say I don't really care" (DT2) } \\
\text { "Quite a bit, but we just tend to deal with } \\
\text { it" (DT2) }\end{array}$ \\
\hline Frustration & $\begin{array}{l}\text { "It's annoying, but I don't mind because } \\
\text { I accept that we're different" (DT1) } \\
\text { "I was just annoyed really, because I was } \\
\text { just trying to help him" (DT2) }\end{array}$ \\
\hline Criticism & $\begin{array}{l}\text { "[T2] would then suggest something } \\
\text { [T1] hadn't done well" (DF) } \\
\text { "I don't really have much faith" (DT2) }\end{array}$ \\
\hline \multicolumn{2}{|l|}{$\begin{array}{l}\text { Type of } \\
\text { separation }\end{array}$} \\
\hline Sport specific & $\begin{array}{l}\text { "I'd rather not play with him" (DT2) } \\
\text { "We wouldn't enjoy just hitting with } \\
\text { each other, or playing together" (DT1) }\end{array}$ \\
\hline General & $\begin{array}{l}\text { "Very different groups of people that } \\
\text { they will do things with" (DM) } \\
\text { "But I like being separate as well" (DT1) }\end{array}$ \\
\hline Identity & \\
\hline Acceptance & $\begin{array}{l}\text { "He knows I am a lot more competitive } \\
\text { and he's not" (DT2) } \\
\text { "We used to be more competitive, but } \\
\text { then I realized he's better" (DT1) }\end{array}$ \\
\hline Characteristics & $\begin{array}{l}\text { "Very individual personalities" (DM) } \\
\text { "We are contrasting characters" (DT2) } \\
\text { "Just shows how different we are" (DT1) }\end{array}$ \\
\hline
\end{tabular}


TWINS AND TALENT DEVELOPMENT 